\title{
Implementing Rural Chronic Care Management: Bridging Gaps and Making a Difference
}

\author{
Knicole Lee* \\ College of Nursing and Health Sciences, Valdosta State University, Georgia, USA
}

*Corresponding author: Knicole Lee, College of Nursing and Health Sciences, Valdosta State University, Georgia, USA.

Received Date: November 08, 2019

Published Date: November 18, 2019

\section{Perspective}

The lack of adequate rural healthcare across the United States is growing at epidemic proportions. Two major things attribute to this problem: the lack of healthcare providers and the growing number residents to these areas.

\section{Rationale for Implementation of Chronic Care Management}

Georgians daily from newborn to elderly must travel great distances or do without primary care treatment due to lack of access in rural areas. More specifically people with special needs from mental health to specific disease issues must wait for appointments up to a month at a time and then travel over 100 miles at times just to get the care for these problems that they need.

Local emergency departments see patients on a daily basis for non-emergent needs due to the lack of the ability to get to or see their specific provider to meet their needs. Children with special needs miss valuable school time as well as parents missing valuable work hours in order to keep appointments for their specific needs. Mental health issues are dealt with in ER's and day treatment centers with no local referral availability or consistent follow-up for services due to lack of availability. Local Departments of Family and Children Services must transport families up to 100 miles one way just to receive counseling services they need.

\section{Benefits of Services for the Public}

Less stress on local ER's and hospitals to provide services to patients not in true emergent state. Increase success rate in schools for children with disabilities through comprehensive care services and management. Increase service provisions and coordination for people with mental health needs so that they can become more stable have greater productivity potential to society and less need for long term in-patient intervention for needs. Increase response time and initial intervention for families in need through the Department of Family and Children Services so that families can become more stable quicker and need less long-term intervention.

\section{Funding Chronic Care Management}

Legislative support that provides stronger funding for healthcare services across the lifespan in these areas of the country is critical to maximizing the potential of people to live long healthy lives and have healthcare close to home. To build a stronger healthcare base to pull from, support needs to begin with legislation that relates to training and facilitating placement of healthcare providers in these rural areas with incentives to stay once they are there and practicing. Support will need to be given to programs that train these providers. Incentives for practitioners to practice in these areas could be supported through such things as, forgiveness of student loans and availability of equipment and resources to effectively and efficiently meet the needs of the population that they will be serving. The facilities with which they will collaborate, and practice need to receive funding for broader services such as telemedicine and specialty modalities as incentives to make their healthcare services available to as many of the communities needs as possible. This financial support would enable facilities to provide these services and have additional providers without draining their limited funding sources that they rely on for day to day operations of their current facilities.

Populations in rural areas are on the rise for many reasons, from the utilization of migrants for agriculture services, to the increase numbers of teen parents and finally the longevity of the current residents and their life spans increasing. With this rise in population comes the need for healthcare in an array of forms. 
Lack of adequate healthcare providers is already apparent and will continue to grow if some intervention is not taken to make an effort to help bridge the healthcare services gap. Through an increase in the availability of local providers, less will be spent of symptom specific care because more effective management and preventive care will be available to residents in these areas. Emergency rooms will be utilized more effectively if services are available and funded in formats so that non-emergent services can be provided in rural health clinics with extended hours and mid-level providers. Employers will lose less money for time off needs of employees if services being sought could be provided in their hometown area by mid-level providers and when needed in collaboration through telemedicine technology. Through support of legislative bills that are currently in committees a strong effort could be made to make rural America a more healthcare accessible place to live. Support for rural health services will not cure all the needs of rural residents but, it will help mend the needs of some and begin to build healthier futures for all rural Americans.

Rationing of healthcare encompasses withholding or not providing all services that may be beneficial to all patients who need the services. Providing these services to those who have to most "potential" to become well from these services and have the most successful outcomes with the least amount of risk. This comes into consideration in areas that are high cost in provision and have high failure rates such as transplants and cancer treatments just to name a couple. Rationing is painful cost containment according to Bodenheimer and Grumbach in 2002 limits are place on medical care that is expected to beneficial to a particular patient. Noted in the text as well, is the use of science as the best guide to providing or withholding treatment dependent upon the probability the treatment will have maximum benefits with minimum harm.

Distributive justice on the other hand puts for the dilemma of all persons receiving the care needed regardless of the ability to pay for the services Bodenheimer and Grumbach. The availability of resources both services related and funding related play a part in this concept as well. When these resources are plentiful there is little debate of who receives what services, but when services become scarce then the ethical principles for which this area is built begin to be bent or broken, sometimes in the form of rationing.

Distributive justice is implemented in our society through emergency room services, programs for mothers to receive nutrition assistance and medical funding if needed while pregnant, for children to receive immunizations, and for infants and children up to five who are income eligible to receive the food and nutritional support they need to assist with growth and early development. Public health is the greatest provider of these distributive justice services. It takes funding and governmental support to make these programs possible, but the positive outcomes far outweigh the potential for negative results without them.

Rationing includes limiting money going to medical care such that not all care expected to be beneficial is provided to all patients Bodenheimer and Grumbach.

However, not all rationing is cost containing. Cost containment limits money going to medical care, but it is not always a result in lack of receipt of care that could be beneficial to patients. Rationing in referred to when the cost control is painful, linking the lack of provision for care that could be beneficial to a patient from being provided. Pain less cost control is not rationing because there is no limitation to specific medical care that is expected to be beneficial. According to Bodenheimer and Grumbach, 2002 painless cost control should always precede painful cost control. Rationing and painful cost control interferes with other areas of medical ethics and practice principles that are expected here in the United States.

\section{Acknowledgement}

None.

\section{Conflict of interest}

No Conflict of interest. 